\title{
Research on the Reform of Tax Collection and Management System by Artificial Intelligence Under the Background of "Intelligence+" Development Strategy
}

\author{
Liu Jing-Yi \\ Finance and Accounting Research Center , Fujian Jiangxia University, Fuzhou, Fujian, China \\ 798013818@qq.com \\ * Liu Jing-Yi
}

Keywords: Artificial intelligence (Al), Tax collection and management, Reform, Suggestion

\begin{abstract}
Artificial intelligence (AI) has become an urgent demand for the development of times, and its application is quite popular in a variety of industries. In the field of tax collection and management, it is also a trend to adopt AI. This is because AI can offer smart services and serve the national "Intelligence +" development strategy, which can not only improve tax efficiency, but also enable effective tax collection and management, regulation, and taxation cost reduction. On the basis of the national "Intelligence +" development strategy, this essay introduces the concept of AI into the field of tax collection and management. It studies the impact of AI application on the national taxation system, and analyzes the necessity of the application. With reference to both domestic and global practices, this essay hopes to offer suggestions to the reform of the taxation risk prevention model and the taxation system. It observes modern taxation administration from a new perspective, and to some extent, aims to guide the reform of the national taxation system.
\end{abstract}

\section{Introduction}

As one of the main directions of the fourth industrial revolution, AI has gained more and more attention from countries around the world. Between 2016 and 2019, China successively issued AI relevant strategy plans such as Internet + AI Three-year Implementation Plan and New Generation AI Development Plan. According to the New Generation AI Development Plan issued by the Sate Council, the market size of AI is expected to exceed 10 trillion yuan by 2030. Also, government reports including China's $13^{\text {th }}$ Five-Year Scientific and Technical Innovation Plan, $13^{\text {th }}$ Five-Year National Strategic Development Plan for Emerging Industries, and the Report of the $19^{\text {th }}$ National Congress of the Communist Party of China, clearly indicate AI as the foundation of industrial transformation and the development of emerging industries. AI is crucial to "rejuvenate the country through science and technology", and encouraging AI innovation is the development focus of industrial upgrading and economic transition.

Although AI application has achieved remarkable achievements in many areas, it standstills in the field of tax collection and management. Along with the development of "Internet + ", there emerges a large number of different and complex economic patterns, which facilitate cross-district or cross-border resource allocation and economic connectivity. In the meantime, e-commerce is developing rapidly; residence income scope is getting broader; and year by year, high income population is increasing. The main mode of China's tax collection and management is "based on optimizing tax services and relied on computer information", and it also highly emphasizes on AI application in the area of big data. However, it is hard for tax authorities to coordinate its specialized operation with traditional tax collection and management and territorial administration. This results in numerous incompatibilities, and therefore, it is necessary to study "Intelligence +" tax collection and management under the strategic background of "Internet +"and "Intelligence+".

\section{The problems of tax collection and management under the background of "Internet+"}

Under the background of "Internet + ", the development of e-commerce has changed the traditional 
business model.Diversified income approaches increase high-income population, which gives rise to a growing demand for tax services. However, the current tax collection and management model is outdated, and has some problems.

\subsection{Information asymmetry of tax collection and management}

The major source for tax authorities to obtain taxation information is either from self-collection or taxpayer declaration. The former requires huge workload and the latter has a lot of uncertainties. Taking personal tax as an example, company withholding and remitting, as well as individual self-declaration are two current tax collection and management modes. The execution of company withholding and remitting is much better than individual self-declaration. One reason is that individuals are not familiar with tax payment standards, and the other is that some individuals are not willing to pay taxes. Uncooperative taxpayers make self-declaration hard to be implemented. Moreover, professional knowledge is required for tax departments to verify self-declared tax information, rather than using relevant information provided by other departments. At the same time, the communication mechanism of tax collection and management also has flaws. Tax departments do not offer enough information exchange channels for taxpayers, and public information is often limited and lagged. Since taxpayers cannot fully express themselves, it is difficult for them to fully comply with government tax legislations and tax policies. These all contribute to the hardship of implementing self-declaration.

\subsection{Taxation manipulation and unfair taxation}

Although AI taxation system relies on coded computer program to carry out tasks, but illegal operation can not avoid. For their personal interests, tax officials may take advantage of job convenience and interpersonal relationship to exploit loopholes of laws and conduct illegal behaviors, which can damage the interest and rights of taxpayers. Also, taxpayers may cheat to avoid tax payment. Such phenomena make legal binding almost void, and law-based tax collection and management difficult to be realized.

\subsection{Low voluntary taxpaying}

Since there are different categories of taxes, not to mention complex tax preferences, many taxpayers who are lack of tax knowledge find it difficult to self-declare. In addition, there are no proper punishment mechanism for those high-income population who do not pay taxes, and no incentive mechanism for those voluntarily pay taxes. Thus, taxpayers cannot realize the benefits and significance of tax paying, which can definitely discourage tax declaration and weaken the implementation of tax declaration system.

\subsection{Inefficient tax collection and management and low inspection accuracy}

Although taxation law is continuedly being improved, there are still gaps for tax evasion. In 2018, actress Fan Bingbing was paid for 30 million yuan, among which 20 million yuan was divided in different contracts. This enabled her to avoid paying 6.18 million personal tax. Besides, the company that Fan Bingbing is the legal representative owed tax of 248 million yuan, among which 134 million yuan was derived from tax evasion. The investigation of this series of "Yin Yang Contracts" was only carried out after receiving reports from the masses. Fan Bingbing is definitely not the only case. There are still many who believe they are lucky enough to stay unexposed.

The reason of inefficient tax collection and management is due to insufficient human resources and highly difficult inspection. To verify the real tax situation, tax officials commonly rely on personal judgement and follow-up manual checks, which takes time and effort. At the price of such high cost, tax officials have to believe that financial accounting data are real. However, no one can really guarantee such reality. 


\section{The impact of AI on tax collection and management under "Intelligence+" development strategy}

Since the implementation of "Internet +" AI Three-Year Plan issued by National Development and Reform Commission in 2016, China has introduced a series of measures in different aspects including scientific technology, application and promotion, and the development of emerging industries, AI has exerted a big influence on different areas and largely improved the convenience of daily life. Even though AI application in the field of tax is still at preliminary stage, it also has far-reaching effects. AI technology as a new intelligence science, its smart operational capability and rapid learning mechanism can easily fit into complex tax reform, and therefore effectively deal with reform related challenges faced by both tax departments and taxpayers.

\subsection{Constructing information exchange platform}

The capacity of information collection and storage is one major feature of AI. Along with its development and application, the physical distance between people is getting shorten. This is especially the case when considering face to face video call, since it must be unbelievable in ancient times when it takes days or even months for a letter to be received. In the past, we relied on newspaper to obtain information from the outside. But now, we can simply stay at home while having access to hundreds of thousands of information from the internet. Information is the most precious treasure in our time. It records the past and predicts the future, and AI can provide a carrier for information storage and transmission. Previously, there are mainly two methods of information exchange for tax collection and management. One is that tax authorities directly announce decisions and resolutions to the masses, and the other is that taxpayers express themselves through soliciting or telephone hotline. Both methods are one-way and unconnected, which cannot facilitate effective information exchange, and result in limited and lagged information disclosure. With more and more high-income population, taxpayers now demand for more taxation information. This strikes the current information exchange methods. Meanwhile, as taxpayers have limited channels to express themselves, their enthusiasm towards tax reform can also be largely discouraged.

The development and application of AI can greatly change this embarrassing situation. There are a lot of information exchange platforms. In the field of taxation, the preliminary goal is to establish a "hearable, visible, and face to face" "taxation interactive service platform", which is expected to achieve information push, enable text enquiry and complaints, provide convenient tax services, fulfill community demand for tax services, preliminarily realize taxation intelligent reform, and facilitate better communication with taxpayers.

\subsection{Guiding and regulating taxpaying}

More than 95\% taxpayers in developed countries can voluntarily declare taxes. The reasons are their emphasize on tax inspection and the application of smart tax collection and management methods. For instance, the US allocates 50\% administrative manpower to tax auditing; tax auditors account for more than half of tax officials in Canada; Japan also has an efficient and strict tax inspection system. Tax awareness is commonly low in China. On the one hand, many individuals have no common sense of the taxation law, and do not see taxpaying as an obligation. On the other hand, the national tax system is often be changed and too complex for many taxpayers. Since AI can be based on big data, by establishing an expert knowledge base, it is possible to offer the best declaration suggestion by analyzing a taxpayer's property, medical insurance and other individualized information. AI technology as a new intelligence science, its learning capability can rapidly fit into complex tax reform, and provide answers to different kinds of tax problems.

\subsection{Strengthening tax department's regulatory capacity}

The uppermost aspect of tax collection and management is tax source management, and losing tax source is the leading cause of inefficient tax source management. Under the background of big data, online and offline taxation are highly integrated. To facilitate development in the tax field, tax collection and management in China also applies a combination of online platforms such as "Online 
Tax Service Center" and offline tax services. This may cause confusion for regulation. To make up the deficiencies, traditional tax departments are equipped with a large number of staffs, in hope of using human resources advantages to solve tax collection and management problem. However, excess human resources make cross-department coordination difficult, and therefore affect efficiency and service quality. In the field of tax collection and management, AI can openly and transparently process information, and therefore effectively achieve tax source management. In the meantime, it can largely downsize tax departments and improve efficiency. Also, using AI to manage tax source is able to effectively control tax risk, form a favorable regulatory system, and strengthen tax department's regulatory capacity.

\subsection{Improving tax efficiency and lowering time cost}

To comply with the trend of the information era, tax departments have gradually accomplished the transform of tax collection and management system from "offline" to "online + offline", and from "invoice-based control" to "information-based control". Previously, under the mode of "invoice-based control", tax department were hard to supervise no-invoice incomes. To pay tax, taxpayers usually had to bring different kinds of certificates to the tax bureau. A long queue was often quite common and the whole process quires patience. With the application of AI, platforms such as "The Third Golden Tax Project" and "Online Tax Service Center" can achieve centralized information processing and management, which largely simplifies the process. Through the internet, taxpayers can enjoy high quality, convenient and comprehensive tax services. With the help of AI, it only takes a few minutes to find out tax loopholes. This not only provides convenience to taxpayers, but also largely reduces time cost of tax authorities when conducting tax inspection.

\section{Suggestions to improve tax collection and management under the application of AI}

In terms of tax administrative affairs, China implements "online + offline" system. Taxpayers can submit required documents either online or offline. This largely improves the efficiency of tax collection and management, and reduces time cost. Due to technical constraint, the application of AI in the taxation field is still at relatively low level. To comply with the need of development and to realize the national AI strategic goal, it is required to accelerate the construction of "Intelligence+" tax collection and management mode.

\subsection{Reinforcing tax education}

The first step is to popularize tax law knowledge. By emphasizing both punishment mechanism and incentive mechanism, the aim of tax education is to increase individuals' tax awareness. In addition, it is necessary to build a complete information exchange platform. At present, AI together with tax collection and management has achieved preliminary development. "The Third Golden Tax Project" centers on taxpayers, by focusing on individual differences, it offers personalized services, including online and telephone counselling, information inquiry and push, as well as resolutions of tax related affairs. However, information exchange between taxpayers and tax departments is still limited, which can easily cause information asymmetry and information lag. With respect to this, it is applicable to make use of the timeliness and transparency of AI in information collecting and feedback, and construct a two-way communication platform to realize information connection.

\subsection{Establishing AI tax supervision system}

The second step focuses on tax departments. The purpose to apply AI in tax collection and management is to effectively manage tax source and tax supervision. Because under the general background of big data, there are conflicts between the development of cross-district or cross-border economy and the complex tax categories and territorial tax management. Different administrative departments are difficult to communicate, and taxation information is also difficult to share. These all affect the improvement of tax collection and management. In addition, when personal interests are taken into consideration, tax collection and management may also subject to moral issues. In this case, on the basis of local management, establishing AI tax supervision system 
to make full use of AI features such as omnipotence, fairness and transparency can achieve refined and scientific tax management, tax leakage prevention, and cost reduction. In combination of the situation in China, it will be more convenient for tax inspection by classifying taxpayers for specialized management. For instance, in terms of company tax source management, AI tax supervision system can conduct tax calculation and storage according to company size and industry category. Furthermore, AI tax supervision system can also help individual taxpayers and tax payment enterprises conduct tax management, and analyze the necessity of tax related affairs according to big data analysis. From this, cost control and even tax burden reduction may become possible. Besides, tax inspection is also an important aspect of tax supervision. However, tax inspection involves numerous items, and due to limited energy, tax inspectors may not necessarily derive accurate calculations. AI tax supervision system will not have such a problem, and inspection accuracy and reliability can be sufficiently improved.

\subsection{Optimizing the construction of AI system platform}

The third step is about AI itself. The current AI relies on human wisdom. Although computer program can be used to conduct operation, manual operation is still inevitable. To further accelerate the construction of "AI + tax collection and management" mode, the application of AI is the key. "The Third Golden Tax Project" is one of the specific manifestations of such mode. By continuously optimizing and promoting "The Third Golden Tax Project", completing the construction of system platform, and improving taxpayers' usage experience, tax collection and management with the help of AI will become more standardized, fair and convenient.

\subsection{Perfecting AI taxation relevant laws and regulations}

Last but not the least, legal construction is an important aspect of national governance, and AI taxation related laws are the guarantee for the construction of "AI + tax collection and management" mode. To accelerate the establishment of AI taxation system, it is necessary to start from laws and regulations. The current tax regulations are too simple and incomplete. To prevent them from being used and exploited, it is crucial to accelerate the rectification of relevant laws. Only with complete laws and regulations, the construction of "AI + tax collection and management" mode can be carried out under protection.

\section{Conclusion}

AI technology as a new intelligence science has become an urgent need for the development of times.Under the general background of national "Intelligence+" development strategy, AI application in the field of tax collection and management provides smart services and serves national strategy. This can not only improve tax efficiency, but can also help tax departments in terms of facilitating effective administration, standardizing taxation and reducing taxation cost. It is for sure that AI can promote the reform of tax collection and management, and at the same time, generate a number of influences. For instance, it is necessary to pay attention to tax department vocational adjustment and the rectification of relevant laws and regulations.

\section{Acknowledgment}

This research was financially supported by Social Science Fund for Cultivating Young Scientific Research Talents in Fujian Jiangxia University(Grant NO. JXS2013015) and Research Topic of Fujian Province's Financial and Tax Law (2018).

\section{References}

[1] Artificial intelligence research group of Logos Data Research Institute, Lu Yufeng, Ma Tao, Wang Sven, Application of artificial intelligence technology in tax collection and management[J], International Taxation in China,2018(05):20-24. 
[2] Weng Wuyao, Ni Shuping. Ways and effects of artificial intelligence to promote modernization of tax collection and administration[J], Taxation Research,2018(06):19-24.

[3] Yuan Jiao, Chen Yanting, Wang Min, Challenges and countermeasures of tax collection and administration in China under the background of "Intelligence+" $[\mathrm{J}]$, Taxation Research, 2018(09):82-88.

[4] Yang Zhiyong, Artificial intelligence, tax policy and taxation theory[J], Taxation Research,2018(06):6-12.

[5] Yan Qing, The concept establishment and system construction of "artificial intelligence+ tax collection and management", Contemporary Economic Management, 2019(02):77-83.

[6] Chen Bing, Cheng Qian, Path of theory and scheme for the construction of AI taxation legal system during AI epoch[J], Lanzhou Academic Journal,2018(11):103-118.

[7] The tax informationization in basic-level tax department under the background of "Intelligence+" ---A case study on D state administration of taxation[D], Shandong University,2018.

[8] Sun Kai, Shen Yuchi. Big data-propeller of constructing modern tax collection and management system, Taxation Research,2015(01):96-99. 